\title{
Analysis of long-term ozone trend over Delhi and its meteorological adjustment
}

\author{
S. Kumari · G. Jayaraman · C. Ghosh
}

Received: 30 April 2012/Revised: 18 September 2012/Accepted: 9 December 2012/Published online: 5 February 2013

(C) Islamic Azad University (IAU) 2013

\begin{abstract}
Present study deals with the statistical analysis of long-term ground level ozone $\left(\mathrm{O}_{3}\right)$ trend and the influence of meteorological variables on its variation over Delhi, India. Daily mean and maximum of $\mathrm{O}_{3}$ and meteorological data, obtained from India Meteorological Department, were arranged for the period of 9 years (1998-2006). Based on the preliminary correlation study of all the data with $\mathrm{O}_{3}$, six variables viz. daily maximum temperature, daily average relative humidity, dew point, wind speed, visibility, and total sunshine were selected. Classical additive time series decomposition technique was used to obtain seasonally adjusted long-term trend. To analyze the masking effect of meteorology, adjustment was made using Kolmogorov-Zurbenko filters followed by stepwise regression analysis to the smoothed series of $\mathrm{O}_{3}$ maximum and meteorological variables, which showed that long-term trend was independent of sunshine duration. Results indicate a significant increasing trend with annual increase of $1.13 \%$ for $\mathrm{O}_{3}$ mean and $3 \%$ for $\mathrm{O}_{3}$ maximum. Annual deseasonalized trend for seasonal cycle shows bimodal oscillations. About $43 \%$ of $\mathrm{O}_{3}$ variation was explained by the selected meteorological factors and rest of variation attributed to factors like emission of precursor gases, pollutant transport, policy changes, etc. Among the three tested regression models, performance of Model 2 with variable temperature, wind speed, and visibility was
\end{abstract}

\footnotetext{
S. Kumari $(\varangle) \cdot$ C. Ghosh

Environmental Pollution Laboratory, Department

of Environmental Studies, University of Delhi,

Delhi 110007, India

e-mail: sunita09@gmail.com

G. Jayaraman

Centre for Atmospheric Sciences, Indian Institute

of Technology, Hauz Khas, New Delhi 110016, India
}

found to be best that resulted in lowering of $\mathrm{O}_{3}$ trend. Large variability $(23 \%)$ was explained by the variable visibility depicted that the emission of primary pollutants not only provides the precursor gases but also control the local photochemical reactions.

Keywords Ground level ozone - Kolmogorov-Zurbenko filters · Meteorological variables · Ozone mean · Ozone maximum - Time series decomposition

\section{Introduction}

Variation of ground level ozone $\left(\mathrm{O}_{3}\right)$ is governed by several factors such as atmospheric phenomenon, area topography, vegetation cover, and the concentration of precursor gasses $\left(\mathrm{CO}, \mathrm{NO}_{x}\right.$, VOCs). All these factors alone or in combination decide the level of ozone in any area. Atmospheric phenomena including incoming solar radiation, turbulence, moisture content, etc. change every second and so are the reactions in atmosphere. These changing atmospheric conditions over time cause temporal variations in $\mathrm{O}_{3}$ concentration. On the global scale, these atmospheric reactions further depend on the physical characteristics of an area like distribution of vegetation, topography, vehicular density, and emission of pollutants, etc. and they cause day-to-day variability in spatial distribution of $\mathrm{O}_{3}$. It is important to understand the variability of $\mathrm{O}_{3}$, both temporal and spatial, as these variations determine their possible impact on the living system (Lin et al. 2001) as $\mathrm{O}_{3}$ is demonstrated to be the most important phytotoxic pollutant, showing growth reductions and visible injuries in plant (Benton et al. 1995). In particular, the variation of $\mathrm{O}_{3}$ can highly affect the radiative forcing (Brasseur et al. 1998), global air quality, and tropospheric chemistry 
(Crutzen 1974; Ashmore and Bell 1991; Shine 2001). Not only the $\mathrm{O}_{3}$ variation, its precursors like $\mathrm{NO}_{x}$ variability can also affect the street canyons and the formation of secondary pollutants in urban areas and thus, important in risk assessment for pedestrians and also for heritage buildings (Sheng and Tang 2012). The regulatory agencies also use the information on $\mathrm{O}_{3}$ variation to identify the locations where vulnerability to natural resources due to ozone may occur (Cooper and Peterson 2000).

Variability in any time series data over a long period follows a pattern or trend and breaking the pattern into different components helps in the better understanding of the data. There are several methods available to identify these components or trend from the original time series. The key step in decomposition involves smoothing of data. The process of decomposition was initially given by Macauley (1931) who introduced ratio-to-moving averages method of decomposition. Later, this method provided the base for the development of several other widely used methods like Census Bureau method developed by US Bureau of Census, X-11, X-11 ARIMA, X-12 ARIMA, etc. The most recent method of decomposition STL (SeasonalTrend decomposition procedure based on Loess) (Cleveland et al. 1990) is widely used method for the data having extreme observations. One of the important application of the decomposition method is to smoothen the exploratory variables that are responsible for the trend cycle by applying filters such as Kalman filters (Kalman 1960), wavelet decomposition (Nason and Silverman 1994) and Kolmogorov-Zurbenko filters (Rao et al. 1992).

Decomposition of time series data of $\mathrm{O}_{3}$ to different components has been extensively used to depict periodicity in data in different geographical locations ( $\mathrm{Wu}$ and Chan 2001; Carslaw 2005; Tripathi et al. 2010). As the formation process of ozone in boundary layer is closely related to temperature, relative humidity, recirculation of air masses, solar radiation duration, and mixing height of tropospheric boundary layer (Sillman 1995; Castell et al. 2008; Tang et al. 2009), use of Kolmogorov-Zurbenko filters (K-Z filters) for meteorological adjustment of ozone has been widely applied in different studies to predict and extract the trend of ozone caused by the meteorological phenomenon (Steinberger 1982; Sebald et al. 2000; Gardner and Dorling 2000; Kuebler et al. 2001; Wise and Comrie 2005; Tu et al. 2007; Azzi and Duc 2008).

The objective of the present study is to observe the temporal changes in ground level ozone concentration and to analyze how these changes are controlled by the meteorological variables in Delhi, India. To begin with, a classical additive time series decomposition technique was used to extract the long-term temporal and short-term seasonal trend for the observed period (1998-2006). Later, meteorological adjustment of time series was made to detect the masking effect of meteorology and the contribution of meteorological factors on long-term ozone variability. Findings depicted a significant increasing trend implying a possible interplay of several factors like emission, transport and meteorology.

\section{Materials and methods}

Description of study area and dataset

The Indian capital Delhi $\left(28^{\circ} 38^{\prime} \mathrm{N}, 77^{\circ} 12^{\prime} \mathrm{E}\right)$ located in the center of great North Indian Gangetic plains (Fig. 1) is an instructive location for the impact of air pollution in an urban area since it is a rapidly expanding center of government, trade commerce, and industry. In recent years, there has been an overall increase in emission of precursor gases mainly contributed from the automobile emission in Delhi (Srivastava et al. 2005; Khillare et al. 2008). During the period of 10 years from 1997 to 2007, reported total number of vehicles circulating has almost doubled and maximum contribution was due to the increase in private vehicles, i.e. cars, jeeps, and motor cycles, which showed almost $50 \%$ increase. In 1998, petrol consumption was

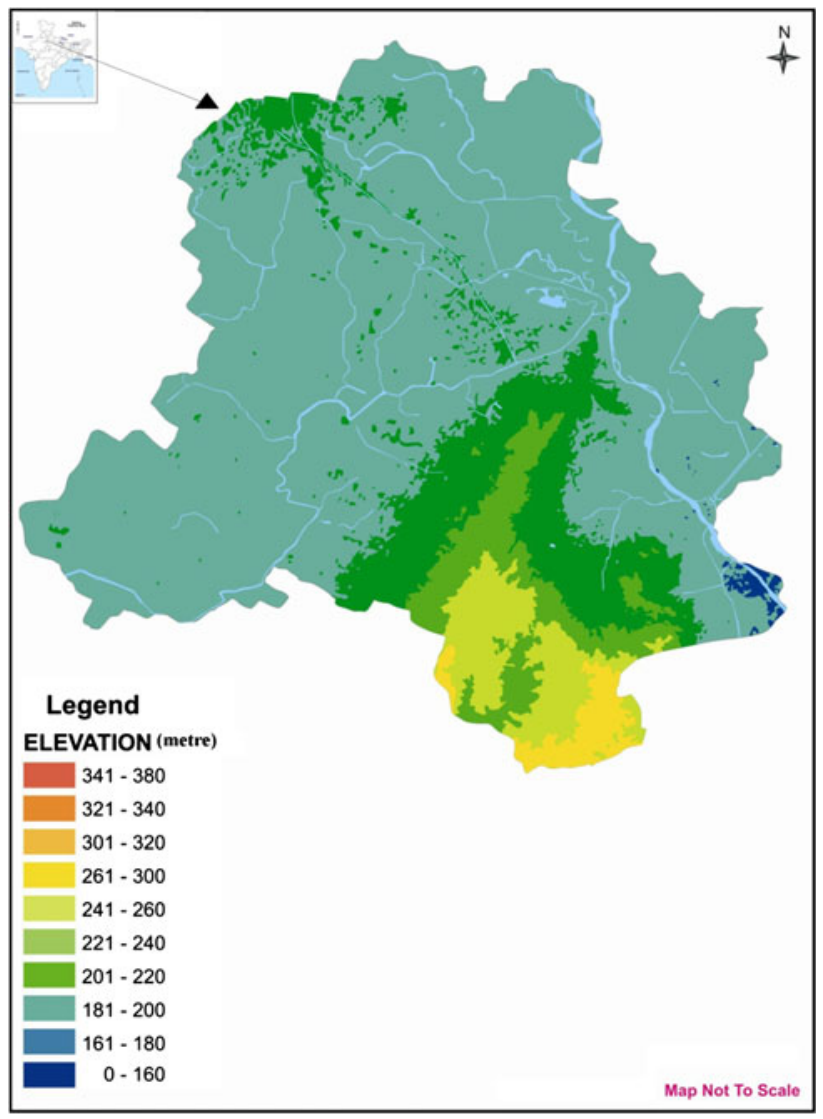

Fig. 1 Physical map of Delhi showing elevations from sea level 
Table 1 Motor vehicles registered and gasoline consumption in Delhi for the period 1997 and 2007

(-) sign signifies decrease

Source: Vehicular

data-Transport Department, Delhi, 2007

Source: Gasoline data-Ministry of Petroleum and Natural Gas, 2007-2008

\begin{tabular}{lrrl}
\hline Vehicle category & \multicolumn{3}{l}{ No. of registered motor vehicles } \\
\cline { 2 - 4 } & \multicolumn{1}{c}{1997} & 2007 & $\%$ increase or decrease \\
\hline Cars and jeeps & 705,923 & $1,599,463$ & 55.8 \\
Motor cycle and scooters & $1,876,053$ & $3,335,763$ & 43.7 \\
Auto rickshaw & 80,210 & 74,200 & $(-) 7.5$ \\
Taxis & 15,015 & 25,891 & 42.1 \\
Buses & 29,572 & 26,491 & $(-) 10.4$ \\
Vehicle goods & 140,922 & 137,983 & $(-) 2.1$ \\
Consumption of petrol (MS) *000tones & 533 & 702 & 24.1 \\
Consumption of diesel (HSD) *000tonnes & 1,242 & 1,326 & 6.3 \\
\hline
\end{tabular}

533 MMT while it was 702 MMT in 2006 (Table 1). Demand in diesel consumption increased from 1,242 MMT to $1,326 \mathrm{MMT}$ attributed to the increasing demand of personal vehicles, which account for more than $90 \%$ of the vehicles in Delhi. The increase in vehicles not only affects the total consumption of fuel but also increases the traffic congestion, vehicles idling time and delay events which ultimately results in more emission of $\mathrm{NO}_{x}$, hydrocarbons, and CO (Shukla and Alam 2010).

Climate of the Delhi is under humid subtropical and semi arid classification influenced by its inland position and can be divided into four seasons as per the classification given by India Meteorological Department (NAAQMS 2001). The four seasons are (i) pre-monsoon or summer (AprilJune), (ii) monsoon (July-September), (iii) post-monsoon (October-November), and (iv) winter (December-March). It is characterized by hot summer with maximum temperature $46{ }^{\circ} \mathrm{C}$ and chilled winter with minimum temperature $3{ }^{\circ} \mathrm{C}$. As many as 8-9 dry months occur during the annual cycle. Average annual rainfall is about $617 \mathrm{~mm}$. During major part of the year, continental type of air prevailed in the region. Winds are predominantly from a westerly or northwesterly direction during all months except monsoon. Easterly and southeasterly winds are common during monsoon (IMD 1991). The subtropical atmosphere of Delhi and large scale emission of precursor gases cause significant increase in the ozone concentration. Sufficient build up of tropospheric ozone has been reported with wide temporal and seasonal variation (Tiwari 1973; Varshney and Aggrawal 1992, 1993; Jain et al. 2005; Ghude et al. 2008).

Ozone and meteorological data for the present analysis were obtained from India Meteorological Department, Pune-the organization working under Ministry of Earth Sciences, Government of India. Monitoring station is located at Lodhi Road, New Delhi and it is designated as Secondary Regional Ozone Centre for Regional Association (Asia) of the World Meteorological Organization (WMO). The station is representative of the urban environment with massive emission of ozone precursors. Since there is no major industry in the nearby area, vehicular emission is the main source of air pollution. Monitoring of ozone is done by an electrochemical continuous ozone sensor (Sreedharan and Tiwari 1971). The sensor part of the equipment has been exposed on the roof of Ozone building at IMD, Lodhi Road at a height of $10 \mathrm{~m}$ above ground. Examination of continuous record of $\mathrm{O}_{3}$ shows that the minimum value occurs in the morning around sunrise (coinciding with minimum temperature) and maximum in the afternoon. This could be explained on the basis of vertical mixing depth, which is minimum in the morning due to formation of stable cool layer near the ground. The depth of vertical mixing is highest in the afternoon due to maximum temperature of the day and the maximum $\mathrm{O}_{3}$ values are nearly representative of the free tropospheric ozone amount. Figure 2 shows the rank-based normal quantile plot of $\mathrm{O}_{3}$ mean and $\mathrm{O}_{3}$ maximum time series. The curves are far from being normal rising upward implying the data to be right-skewed with large variance. Some of the daily missing data ( $3 \%$ of $\mathrm{O}_{3}$ and $8.2 \%$ of meteorological data) were interpolated using linear interpolation.

Based on the preliminary correlation study of all the meteorological variables with ozone, daily maximum of air temperature $\left(T_{\max },{ }^{\circ} \mathrm{C}\right)$, daily average of relative humidity $\left(\mathrm{RH}_{\mathrm{avg}}, \%\right)$, daily average of dew point temperature (DP $\mathrm{avg}$, ${ }^{\circ} \mathrm{C}$ ), daily average of wind speed ( $\mathrm{WS}_{\mathrm{avg}}, \mathrm{km} \mathrm{h}^{-1}$ ), daily average of visibility $\left(V_{\mathrm{avg}}, \mathrm{km}\right)$, and total sunshine hour (TS, h) were selected. Correlation between $\mathrm{O}_{3}$ maximum and meteorological variables has been discussed analyzed in "Sect. 3.3". The daily mean of ozone $\left(\mathrm{O}_{3}\right.$ mean) and daily maximum of $\mathrm{O}_{3}\left(\mathrm{O}_{3}\right.$ maximum $)$ data and meteorological variables were arranged for the period of 9 years (1998-2006).

Descriptive statistics of meteorological data is given in Table 2. To apply the $\mathrm{O}_{3}$ data for the estimation of linear trend, monthly average of $\mathrm{O}_{3}$ were calculated which resulted in the total number of observations $(n)=108$. For the meteorological adjustment, daily data were transformed to natural log form to imply the assumption of linearity and to stabilize the variance in series. Statistical analysis was done using SPSS 16.0. 


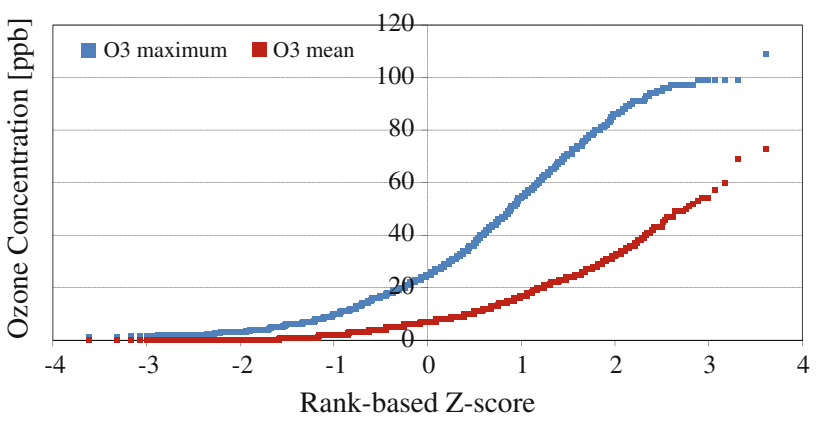

Fig. 2 Rank-based normal quantile plot of $\mathrm{O}_{3}$ mean and $\mathrm{O}_{3}$ maximum

Table 2 Descriptive statistics of meteorological data

\begin{tabular}{lrrrrrr}
\hline & $T_{\max }$ & $\mathrm{DP}_{\mathrm{avg}}$ & $\mathrm{Rh}_{\text {avg }}$ & $V_{\text {avg }}$ & $\mathrm{WS}_{\text {avg }}$ & \multicolumn{1}{c}{$\mathrm{TS}$} \\
\hline Mean & 30.5 & 14.5 & 56.9 & 2.6 & 6.2 & 6.8 \\
Minimum & 7.0 & 0.0 & 11.0 & 0.0 & 0.0 & 0.0 \\
Maximum & 46.0 & 30.0 & 100.0 & 7.0 & 50.0 & 19.0 \\
25 percentile & 25.0 & 9.0 & 44.0 & 2.0 & 2.0 & 4.8 \\
Median & 32.0 & 14.0 & 57.0 & 3.0 & 5.0 & 7.1 \\
75 percentile & 36.0 & 21.0 & 70.0 & 3.0 & 10.0 & 8.7 \\
Variance & 55.0 & 44.5 & 335.0 & 1.2 & 29.0 & 12.1 \\
SD & 7.4 & 6.7 & 18.3 & 1.1 & 5.4 & 3.5 \\
Skewness & -0.4 & 0.2 & -0.1 & 0.1 & 1.1 & 0.5 \\
Kurtosis & -0.5 & -1.1 & -0.6 & -0.2 & 1.9 & 1.9 \\
\hline
\end{tabular}

Trend analysis procedure

Parametric and non-parametric methods of significance test were done to find whether data exhibit a trend (EPA 2006). In order to assess the underlying trend in $\mathrm{O}_{3}$ time series data, two approaches of trend analysis were applied. (i) Estimation of long-term seasonally adjusted $\mathrm{O}_{3}$ trend with monthly seasonal indices and the annual growth rate of $\mathrm{O}_{3}$ ("Testing trend in the time series"). (ii) Estimation of meteorologically adjusted $\mathrm{O}_{3}$ trend using KolmogorovZurbenko filter to filter the $\mathrm{O}_{3}$ maximum and meteorological data series followed by stepwise regression analysis ("Monthly variation of ozone mean-maximum and annual trends").

\section{Estimation of long-term $\mathrm{O}_{3}$ trend-cycle and its seasonal components}

For the estimation of trend components at time $t$, method of classical additive time series decomposition technique was applied to original $\mathrm{O}_{3}$ time series $\left(O_{t}\right)$.

$O_{t}=T_{\mathrm{t}}+S_{\mathrm{t}}+E_{\mathrm{t}}$

where $T_{\mathrm{t}}$ is long-term trend-cycle component which represents overall increase or decrease, $S_{\mathrm{t}}$ is the seasonal component due to seasonal variations, and $E_{\mathrm{t}}$ is the shortterm variation component called as irregular (or remainder) component. Ordinary least square regression technique with time $\mathrm{t}$ as the independent variable and $\mathrm{O}_{3}$ data $\left(O_{t}\right)$ as dependent variable was applied to estimate the growth rate of the $\mathrm{O}_{3}$ per year.

i.e., $T_{\mathrm{t}}=b_{0}+b_{1} \mathrm{t}$

where $b_{0}$ is the $y$-intercept and $b_{1}$ is the slope of the regression line. $b_{1}$ gives the estimate of trend. The composite annual mean of the trend estimate gives the percentage of change per year.

The long-term trend-cycle $\left(T_{\mathrm{t}}\right)$ of $\mathrm{O}_{3}$ mean and $\mathrm{O}_{3}$ maximum was computed using 12 moving averages with single iteration. Using the obtained trend-cycle values, the actual ozone data was de-trended $\left(O_{\mathrm{t}}-T_{\mathrm{t}}\right)$. By taking the monthly averages of de-trended values for each month, seasonal indices $\left(S_{\mathrm{t}}\right)$ were estimated. The monthly seasonal index was the average deviation of each month's ozone value from the ozone level that was due to the other components in that month. Annual average of the difference between actual ozone and its seasonal index $\left(O_{\mathrm{t}}-S_{\mathrm{t}}\right)$ gives the seasonally adjusted ozone trend in which the influence of seasonal fluctuations was smoothened.

\section{Meteorologically adjusted long-term $\mathrm{O}_{3}$ trend}

Application of $K Z$ filter It is well known that ozone concentration is influenced by meteorological variables like temperature, humidity, visibility, solar insolation, synoptic movements, and emission variables such as ozone precursor and scavenger gases. The meteorological fluctuations in a long-term trend may suppress the underlying trend. In order to obtain meteorologically adjusted $\mathrm{O}_{3}$ trend, Kolmogorov-Zurbenko filters (KZ filter) (introduced by Rao et al. 1992) for time series decomposition was applied to separate both ozone and meteorological data into short-term, seasonal and long-term components. Separation helps in smoothening of data, which is amenable to further application of regression analysis. A time series of filtered $\mathrm{O}_{3}$ data $[O(t)]$ can be represented as

$O(t)=T(t)+S(t)+E(t)$

where $T(t)$ is the long-term trend component, $S(t)$ is seasonal variation, and $E(t)$ is the short-term component. In this section, according to Rao and Zurbenko (1994), the shortterm component is attributed to weather and short-term fluctuations in precursor emissions. Seasonal component is a result of changes in solar angle, and the long-term trend results from changes in overall emissions and pollutant transport, climate and policies. The KZ filter is low pass filter produced through repeated iterations of a moving average which is defined by the formula given below 
$Y t=\frac{1}{m} \sum_{j=-k}^{k} X(t+j)$

where $k$ is the number of values included on each side of the targeted value and the window length $m=2 k+1$. The output of the first pass then becomes the input for the next pass. $\mathrm{KZ}_{(15,5)}$ filter (15-day length [m] with five iterations $[p])$ was applied to the natural $\log$ of $\mathrm{O}_{3}$ maximum that produced a time series which was devoid of short time variations denoted by $\mathrm{O}_{\mathrm{BL}}$. Meteorological variables were also filtered in a similar manner and denoted by $\mathrm{M}_{\mathrm{BL}}$. These serve as baseline components of air quality which can be defined as the sum of the long-term and seasonal components:

Baseline $(t)=\mathrm{KZ}\left({ }_{15,5)}=T(t)+S(t)\right.$

The short-term time series was produced by subtracting the baseline from the original times series data

$E(t)=O(t)-\mathrm{KZ}_{(15,5)}$

For the extraction of long-term annual cycle, a $\mathrm{KZ}_{(365,3)}$ filter was used creating a time series containing cycles with periods $>632$ days. This results in long-term component of the original air quality time series $[e(t)]$. Thus,

$S(t)=\mathrm{KZ}_{(15,5)}-\mathrm{KZ}_{(365,3)}$

During the filtering process, data was truncated both in the beginning and in the end of series because of repeated iterations of moving average. Longer window lengths result in additional data lost and truncated trend component. In the foregoing manner each of the meteorological variables was also separated as a different component. Figure 3 summarizes $O(t)$ Fig. 3a) and its different components obtained by applying $\mathrm{KZ}$ filters. Seasonal component $[S(t)]$ (Fig. 3b) was due to the changes in solar cycle, short-term component $[E(t)]$ (Fig. 3c) was the day-to-day variability that occurred because of meteorology and precursors emission and long-term component $[T(t)]$ (Fig. 3d) was due to the long-term changes in ozone concentration because of several factors like emission of precursors, changes in land use pattern, policy implications, climatic variability, occurrence of special events, etc.

Development of KZ filter model With the chosen KZ filter, a multiple stepwise linear regression was performed for the baseline component and short-term component using filtered natural $\log$ of ozone concentration $\left[O_{\mathrm{KZ}}(t)\right]$ on filtered temperature $\left[T_{\mathrm{KZ}}(t)\right]$, relative humidity $\left[R H_{\mathrm{KZ}}(t)\right]$, dew point temperature $\left[D_{\mathrm{KZ}}(t)\right]$, visibility $\left[V_{\mathrm{KZ}}(\mathrm{t})\right]$ wind speed $\left[W_{\mathrm{KZ}}(t)\right]$ and total sunshine hour $\left[T S_{\mathrm{KZ}}(t)\right]$. Initially, attempt was made to enter six meteorological variables (independent variables) but there was problem of multicollinearity caused by dew point average $\left[\mathrm{DP}_{\text {avg }}\right]$. Hence later, only five meteorological variables were considered. As suggested by stepwise regression analysis, three sets of models were developed: (i) Model 1 (one predictor model) a single predictor $\left(T_{\max }\right)$ was entered, (ii) Model 2 (three predictor model) with three predictors $\left(T_{\max }, \mathrm{WS}_{\mathrm{avg}}\right.$, and $V_{\text {avg }}$ ), and (iii) Model 3 (five predictor model) in which all the variables were entered. Explanation of each model developed is given in appendix I. Two equations for each model were obtained by substituting the resultant regression coefficient values given in Table 7 in Appendix. Variance explained by each model (Table 8 in Appendix) was increased by the inclusion of new variable to the model. The selected variables were able to explain $23-43 \%$ of the variance while rest of the variation in data was because of the factors other than the selected meteorological variables. The models were significant at $p<0.01$ level of significance.

The residuals of baseline $\left(\mathrm{KZ}_{15,5}\right)$ and seasonal $\left(\mathrm{KZ}_{15,5^{-}}\right.$ $\mathrm{KZ}_{365,3}$ ) components were then added up and to the sum of residuals for each model, a $\mathrm{KZ}_{(365,2)}$ filter was applied which resulted in the long-term meteorologically adjusted ozone residuals $\left[\left(\varepsilon(t)_{L T}\right]\right.$. The residual $\left[\left(\varepsilon(t)_{L T}\right]\right.$ for each model was then added to the average of $\mathrm{KZ}_{(365,3)}$ filtered long-term trend of the original data series $\left[\mathrm{e}(\mathrm{t})+\varepsilon(\mathrm{t})_{\mathrm{LT}}\right]$. This resulted in the long-term meteorologically adjusted $\mathrm{O}_{3}$ trend residuals $\left[\mathrm{O}_{\mathrm{LTadj}}\right]$. The residual value was then converted to its exponent to improve the visual representation and meaningful interpretation with unadjusted ozone trend. The meteorological adjustment of the long-term trend explains the variation in ozone concentration due to the factors other than the selected meteorological variables by each model.

\section{Results and discussion}

Testing trend in the time series

For the parametric approach of trend test, one sample student $t$ test was examined. Test was based on testing the null hypothesis $H_{0}$ (there was no trend) against the alternative hypothesis $H_{1}$ (there was trend) in time series. Table 3 shows the obtained value of student's $t$ test with $(n-2)$ degrees of freedom ( $n$ chosen as 108) as 3.04 for $\mathrm{O}_{3}$ mean and 1.88 for $\mathrm{O}_{3}$ maximum. Table value for $t_{0.05}=1.64$ as table value for 106 degrees of freedom tends to infinity. The trend values for both the series were found to be significant at $5 \%$ level of significance and thus, the null hypothesis of no trend was rejected and it was concluded that there exists a trend in $\mathrm{O}_{3}$ time series. 
Fig. 3 Ozone maximum time series and its different components decomposed by $\mathrm{KZ}$ filter: a original $\mathrm{O}_{3}$ time series $[O(t)]$ before application of $\mathrm{KZ}$ filters; b Seasonal component [S(t)]; c short-term component $[E(t)]$; and $\mathbf{d}$ Long-term trend component $[T(t)]$
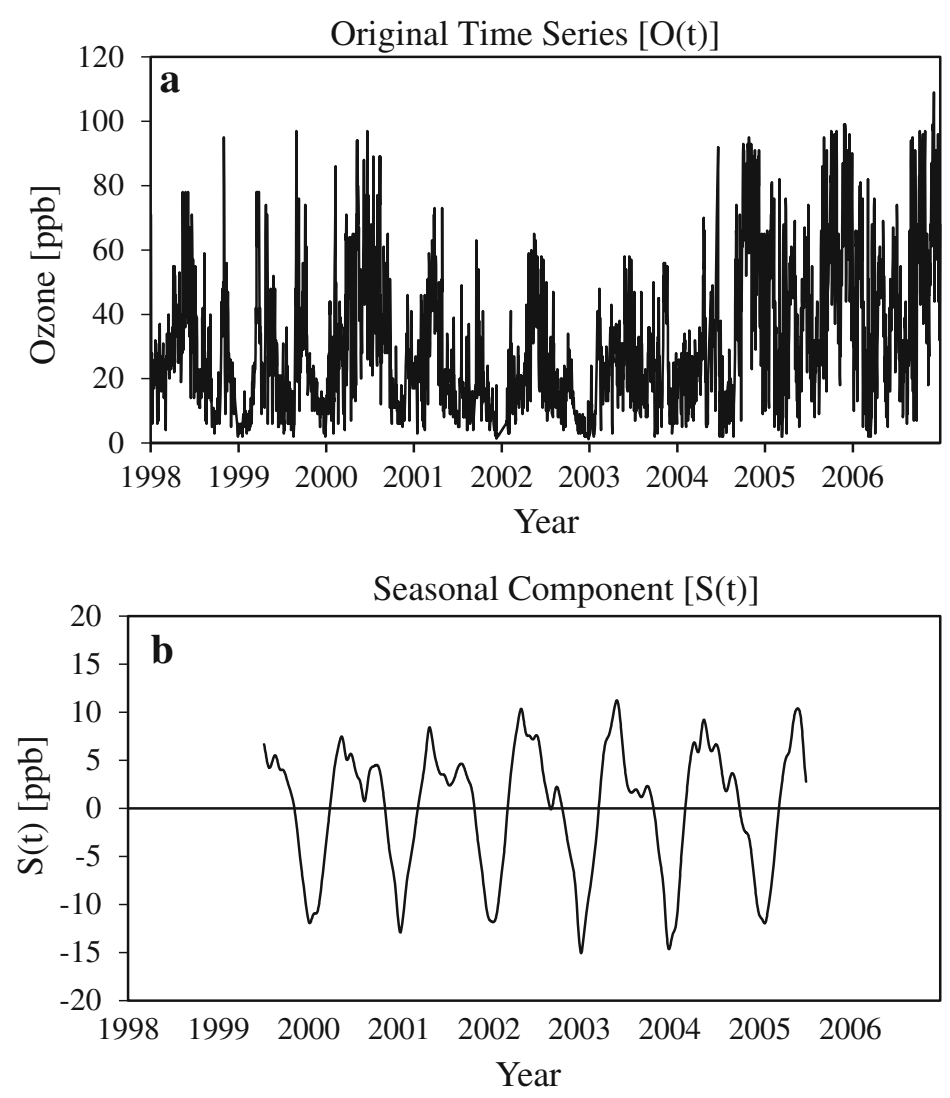

Short-Term Component [E(t)]
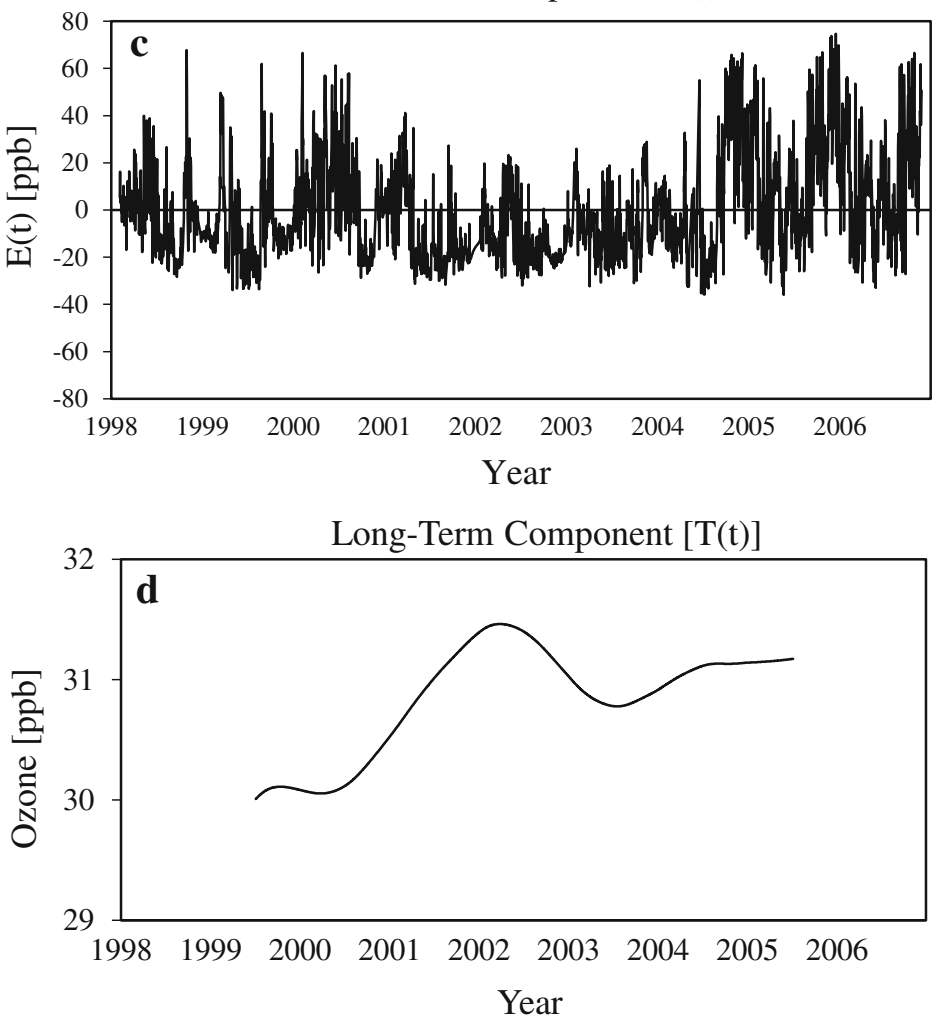
Table 3 Parametric Student's $t$ test for significance trend test

\begin{tabular}{|c|c|c|c|c|c|c|}
\hline \multirow[t]{2}{*}{ Model } & \multirow[t]{2}{*}{ Dependant variable } & & \multicolumn{2}{|c|}{ Unstandardized coefficients } & \multirow{2}{*}{$\begin{array}{l}\text { Standardized coefficients } \\
\text { Beta }\end{array}$} & \multirow[t]{2}{*}{ Student's $t$ test } \\
\hline & & & B & SE & & \\
\hline \multirow[t]{2}{*}{1} & Ozone (mean) & (Constant) & 10.05 & 1.75 & & 5.75 \\
\hline & & $\mathrm{T}$ & 0.08 & 0.03 & 0.28 & $3.04 *$ \\
\hline \multirow[t]{2}{*}{2} & Ozone (max) & (Constant) & 48.09 & 4.59 & & 10.46 \\
\hline & & $\mathrm{T}$ & 0.14 & 0.07 & 0.18 & $1.89 * *$ \\
\hline
\end{tabular}

* Significant at $p<0.05$

** Significant at $p<0.01$

Table 4 Results of non-parametric Mann-Kendall trend tests

\begin{tabular}{lcc}
\hline Kendell statistics & $\mathrm{O}_{3}$ mean & $\mathrm{O}_{3}$ maximum \\
\hline$S$ & 813 & 630 \\
$Z_{0}$ & 2.159 & 1.67 \\
$Z_{0.95}$ & 1.645 & 1.645 \\
\hline
\end{tabular}

Table 5 Seasonal indices $[S(t)]$ for ozone mean and ozone maximum over the period $1998-2006$

\begin{tabular}{lcc}
\hline Month & $\begin{array}{l}\text { Ozone mean index value } \\
( \pm \text { SD })\end{array}$ & $\begin{array}{l}\text { Ozone maximum index } \\
\text { value }( \pm \text { SD })\end{array}$ \\
\hline January & $-4.9( \pm 4.99)$ & $-11.5( \pm 20.58)$ \\
February & $-2.7( \pm 4.14)$ & $-2.9( \pm 16.04)$ \\
March & $2.8( \pm 8.81)$ & $3.4( \pm 15.2)$ \\
April & $4.75( \pm 4.19)$ & $7.2( \pm 14.9)$ \\
May & $3.26( \pm 8.48)$ & $6.5( \pm 18.07)$ \\
June & $4.5( \pm 7.36)$ & $8.5( \pm 17.72)$ \\
July & $-2.6( \pm 6.86)$ & $0.03( \pm 17.6)$ \\
August & $-1.7( \pm 6.64)$ & $0.6( \pm 19.16)$ \\
September & $0.4( \pm 5.74)$ & $1.1( \pm 13.97)$ \\
October & $1.4( \pm 10.85)$ & $1.7( \pm 17.09)$ \\
November & $-2.4( \pm 7.22)$ & $-5.16( \pm 25.43)$ \\
December & $-4.6( \pm 3.68)$ & $-19.7( \pm 17.47)$ \\
\hline
\end{tabular}

Table 4 display the results of rank-based non-parametric Mann-Kendall test. It was observed that the values of test statistics $\left(Z_{0}\right)$ were greater than $Z_{0.95}$, therefore the null hypothesis of no trend was rejected at $5 \%$ significance level $(\alpha=0.05)$. Large positive value of $S$ ' statistics indicates the presence of increasing trend in the data.

Monthly variation of ozone mean-maximum and annual trends

Monthly values of the detrended $\mathrm{O}_{3}$ series averaged over the period 1998-2006 as given in Table 5 shows a welldefined annual cycle for the period. The highest index value for $\mathrm{O}_{3}$ mean was in April and for $\mathrm{O}_{3}$ maximum, it was in June. Lowest index value was in DecemberJanuary. Deseasonalized trend in a year for seasonal cycle shows bimodal oscillations with a major peak in summer (April-June) and a minor peak during post-monsoon (October) period. Summer peak of ozone corresponds to maximum photochemical reactions and decreased rate of $\mathrm{O}_{3}$ dissociation process. As discussed by Jain et al. (2005), during summer and autumn (post-monsoon) period, incidences of the occurrence of anticyclonic conditions associated with sunny warm period, stagnant wind patterns and low humidity are increased, which provide favorable atmospheric conditions for photochemical reactions. Availability of favorable atmospheric conditions and presence of high concentration of precursor gases $(\mathrm{CO}$, VOCs, $\mathrm{NO}_{x}$ ) emitted from local vehicles and transported from nearby regions, results in the increased rate of $\mathrm{O}_{3}$ formation. Build up process was further enhanced by lowering the dissociation process of $\mathrm{O}_{3}$ as low humidity level of atmosphere during summer controls the $\mathrm{O}_{3}$ photolysis process.

Annual trend of $\mathrm{O}_{3}$ is the overall movements of time series values which show the overall tendency of data whether values are increasing or decreasing over time. The slope of regression trend line measures the rate of change of a linear trend over given time period. Figure 4 depicts the results of linear trend and cyclic-trend of time series decomposition of the monthly $\mathrm{O}_{3}$ mean and maximum. There was gradual increase in trend component in the period 1998-2006. The upward/increased trend of ozone time series indicates the deterioration of air quality most possibly due to the increased emission of precursors in Delhi. The general growth trend line fitted to the data indicates the overall increase in the temporal variation at the rate of $1.13 \%$ for $\mathrm{O}_{3}$ mean and $3 \%$ for $\mathrm{O}_{3}$ maximum per year which results from overall emissions, climate, pollutant transport, economical development and urbanization process. This was the estimated increase of ozone over long time period (1998-2006) in which trend direction for shorter period was not considered. 
Fig. 4 Annual variation of ozone mean and maximum with combined trend-cycle $\left(T_{\mathrm{t}}\right)$. Linear trend 1 and 2 denotes the regression trend line for monthly $\mathrm{O}_{3}$ mean and monthly $\mathrm{O}_{3}$ maximum, respectively

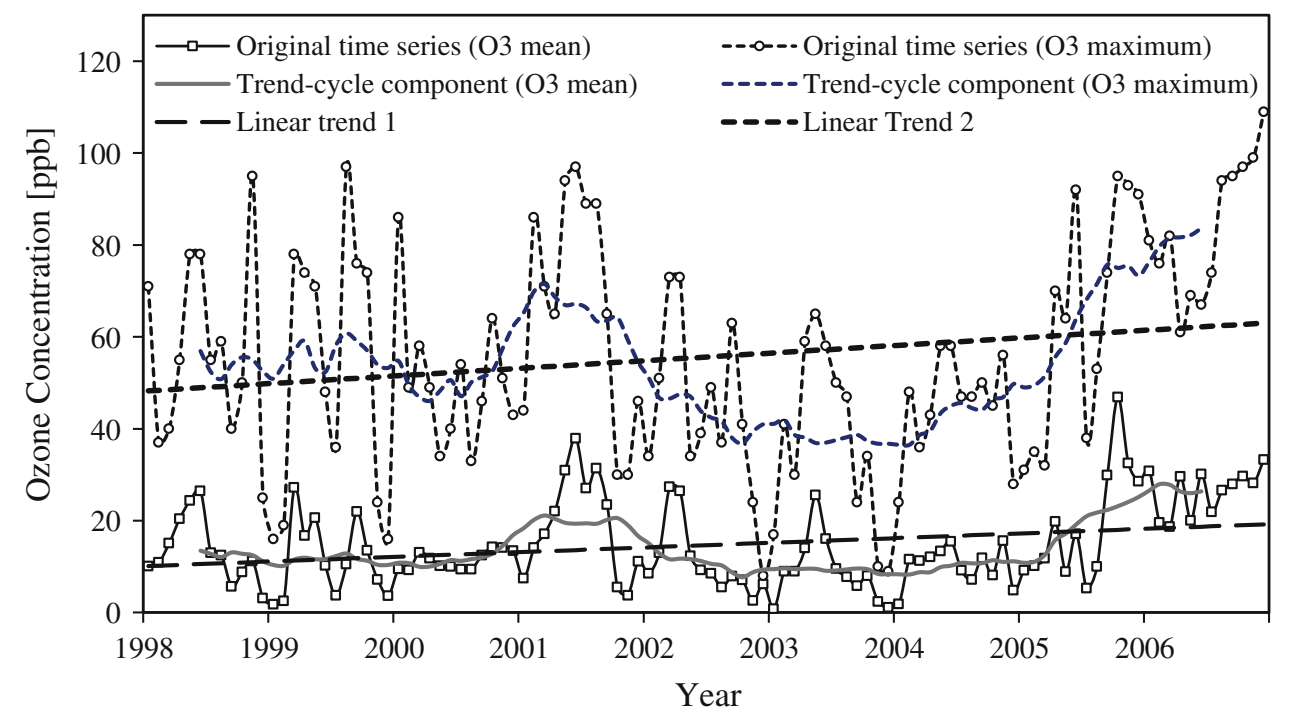

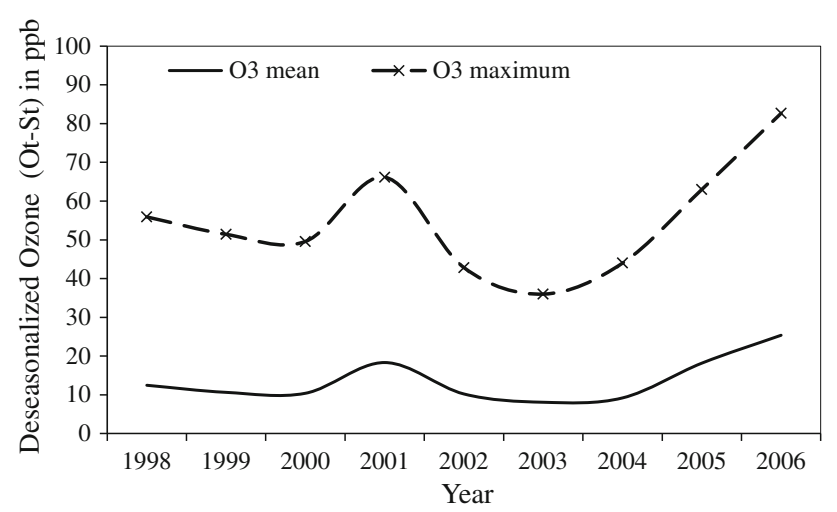

Fig. 5 Annual trends of deseasonalized $\mathrm{O}_{3}$ mean and $\mathrm{O}_{3}$ maximum

As the duration of test period was critical to the trend analysis, trend direction for the short period may be different and overlooked in longer period. Plots of annual averages of the deseasonalized concentration values $\left(O_{\mathrm{t}}-S_{\mathrm{t}}\right)$ are plotted in Fig. 5. Short-term variation in the $\mathrm{O}_{3}$ mean and maximum is visualized from the plot. During the initial period (1998-2000), $\mathrm{O}_{3}$ levels were relatively steady and then, there was sudden increase in 2000-2001 followed by decrease in 2002-2003. From 2004 onwards, there was a steep increase in the ozone concentration. In 2000-2001, there was substantial increase in the $\mathrm{O}_{3}$ maximum values with increase in both day and night time concentrations.

Effect of meteorological factors and its adjustment to ozone time series

Effects of meteorological factors were examined with correlation analysis for the unadjusted (original) ozone and meteorological variables. As the $\mathrm{O}_{3}$ concentration showed large seasonal variability, it was expected that the dependence on meteorological variables might be seasonal. Hence, the data sets for Pearson bivariate correlation were classified into four groups: summer, monsoon, post monsoon, and winter. The results are given in Table 6 .

The established correlation coefficient values between ozone and meteorology were not very high but the association was significant at $p$ value $<0.01$ and 0.05 level of significance. Analysis based on the annual data showed that $T_{\text {max }}, \mathrm{DP}_{\text {avg }}, V_{\text {avg }}, \mathrm{WS}_{\text {avg }}, \mathrm{TS}$, were all positively correlated and $\mathrm{RH}_{\text {avg }}$ was negatively correlated to maximum ozone. Further analysis based on seasonal data revealed that the effect of each variable was different in different seasons. $T_{\max }$, which had positive and significant association during summer and winter, did not show any significant contribution during monsoon. During monsoon, significant and positive correlation with humidity was obtained. This needs further justification for this type of association. During post monsoon period, the maximum ozone variation was found to be independent of temperature and sunshine duration (as negative association established), it was largely governed by wind speed. Thus, the correlation coefficient result indicates that, in total, all the meteorological variables had significant role in maximum ozone variation which varies with different seasons.

With the meteorologically adjusted KZ filtered trend as shown in Fig. 6, performance of models changed with the addition of a new variable to the model. Adjustment for temperature (Model $1-1$ predictor model) results in the further elevation of $\mathrm{O}_{3}$ peak in 2000-2001 and 2005-2006. Temperature, visibility, and wind speed were positively correlated, and the adjusted trend after the combination of these factors in model 2, ozone was pushed lower to the unadjusted trend. Relative humidity $\left(\mathrm{RH}_{\mathrm{avg}}\right)$ and total sunshine (TS) were negatively correlated to $\mathrm{O}_{3}$ and inclusion of these two variables in Model 3 (5-predictor model) 

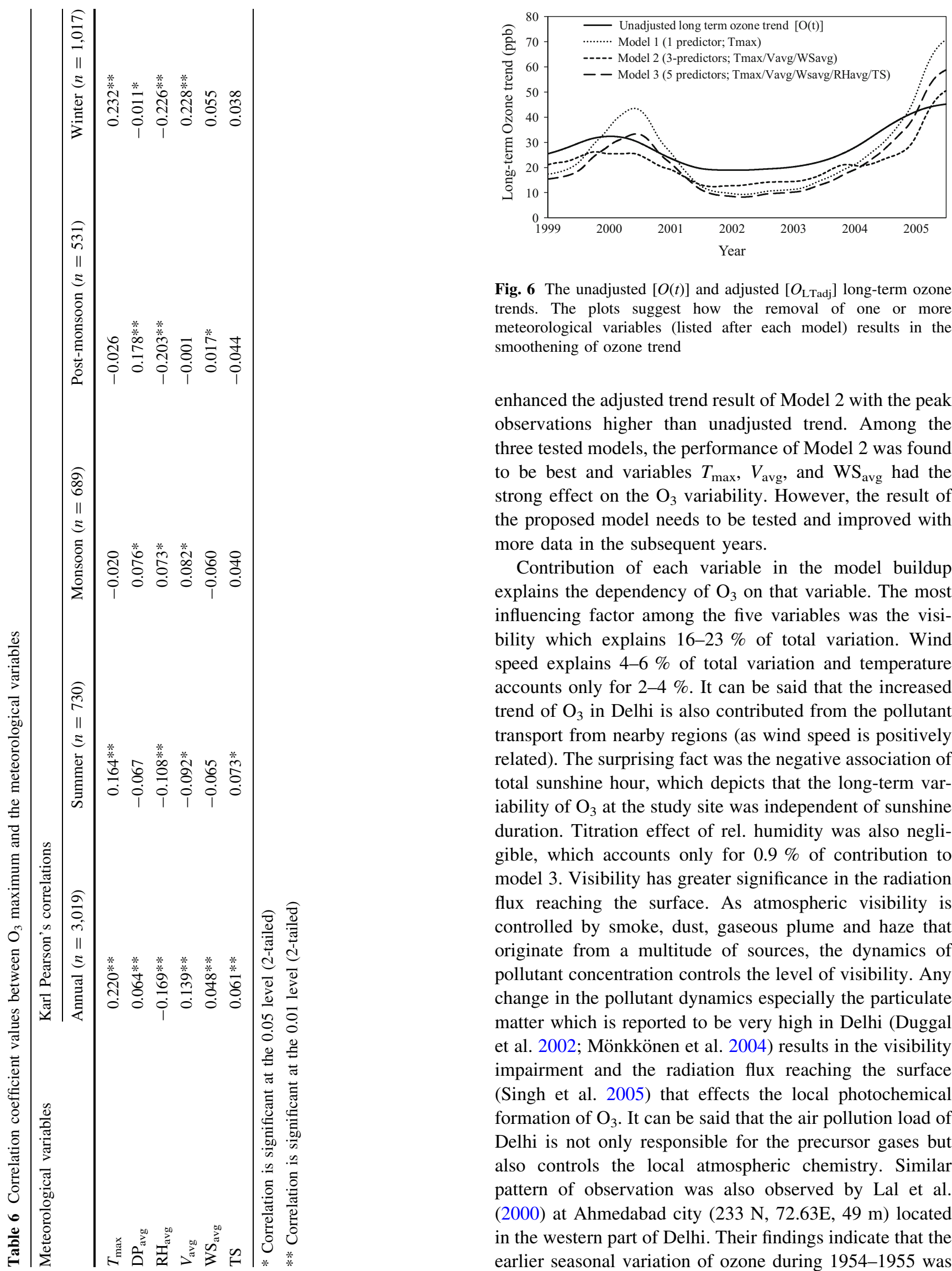

Fig. 6 The unadjusted $[O(t)]$ and adjusted $\left[O_{\text {LTadj }}\right]$ long-term ozone trends. The plots suggest how the removal of one or more meteorological variables (listed after each model) results in the smoothening of ozone trend

enhanced the adjusted trend result of Model 2 with the peak observations higher than unadjusted trend. Among the three tested models, the performance of Model 2 was found to be best and variables $T_{\max }, V_{\text {avg }}$, and $\mathrm{WS}_{\text {avg }}$ had the strong effect on the $\mathrm{O}_{3}$ variability. However, the result of the proposed model needs to be tested and improved with more data in the subsequent years.

Contribution of each variable in the model buildup explains the dependency of $\mathrm{O}_{3}$ on that variable. The most influencing factor among the five variables was the visibility which explains $16-23 \%$ of total variation. Wind speed explains $4-6 \%$ of total variation and temperature accounts only for 2-4\%. It can be said that the increased trend of $\mathrm{O}_{3}$ in Delhi is also contributed from the pollutant transport from nearby regions (as wind speed is positively related). The surprising fact was the negative association of total sunshine hour, which depicts that the long-term variability of $\mathrm{O}_{3}$ at the study site was independent of sunshine duration. Titration effect of rel. humidity was also negligible, which accounts only for $0.9 \%$ of contribution to model 3. Visibility has greater significance in the radiation flux reaching the surface. As atmospheric visibility is controlled by smoke, dust, gaseous plume and haze that originate from a multitude of sources, the dynamics of pollutant concentration controls the level of visibility. Any change in the pollutant dynamics especially the particulate matter which is reported to be very high in Delhi (Duggal et al. 2002; Mönkkönen et al. 2004) results in the visibility impairment and the radiation flux reaching the surface (Singh et al. 2005) that effects the local photochemical formation of $\mathrm{O}_{3}$. It can be said that the air pollution load of Delhi is not only responsible for the precursor gases but also controls the local atmospheric chemistry. Similar pattern of observation was also observed by Lal et al. (2000) at Ahmedabad city (233 N, 72.63E, 49 m) located in the western part of Delhi. Their findings indicate that the earlier seasonal variation of ozone during 1954-1955 was 
dominated by solar radiation but during 1991-1995, the variation was dominated by pollutants.

\section{Conclusion}

The study deals with the statistical analysis of long-term ozone trend in an urban environment Delhi with high emission of ozone precursor gases. The study site has been designated as one of the regional ozone monitoring station for Asia by WMO. This is the first time such a statistical analysis for trend estimation and its meteorological adjustment using $\mathrm{K}-\mathrm{Z}$ filters for ground level $\mathrm{O}_{3}$ is made for Delhi. The preliminary findings of this study revealed a significant increasing trend of $\mathrm{O}_{3}$ over the period 1998-2006 with overall increase of $1.13 \%$ per year for $\mathrm{O}_{3}$ mean and $3 \%$ per year for $\mathrm{O}_{3}$ maximum. A well-defined seasonal cycle exists with two annual peaks, major in summer (April-June) and minor during post-monsoon (October) period. The study is able to propose a statistical model relating $\mathrm{O}_{3}$ with meteorological variables that expressed the observed phenomenon adequately. About $43 \%$ variation of ozone is explained by the meteorological factors. Rest of the contribution is attributed to other factors which can be due to the emission of precursor gases, vehicle density, pollutant transport, policy changes, economic development, or urbanization process. Adjustment of the ozone trend to meteorology reveals the fact that temperature, visibility and wind speed were the important meteorological predictors for the long-term $\mathrm{O}_{3}$ trend in Delhi and among these three variables, visibility plays the most important role. The long-term variation of $\mathrm{O}_{3}$ was independent of the sunshine duration. The findings need to be confirmed with more data for the subsequent years. Emission of primary pollutants was not only responsible for the precursor gases $\left(\mathrm{CO}, \mathrm{NO}_{2}, \mathrm{VOCs}\right)$ for the $\mathrm{O}_{3}$ production but also for the local atmospheric chemistry. Significant increasing trend indicates that the air quality in the area continues to deteriorate in spite of the several mitigation processes undertaken to improve the air quality. The measures taken during the period 1996-2005 to reduce the precursor loads were not effective enough and further reduction in emissions especially from transportation sources are strongly recommended.
Acknowledgments Authors are thankful to India Meteorological Department, Pune, India for providing the data for ozone and relevant meteorological variables.

\section{Appendix I}

The pragmatic form of regression model that express the relationship between the dependent (filtered ozone) and independent (filtered meteorological) variables are expressed as:

$$
\text { Model 1: } \mathrm{O}_{\mathrm{KZ}}(\mathrm{t})=\mathrm{b}_{0}+\mathrm{b}_{1} \mathrm{~T}_{\mathrm{KZ}}(\mathrm{t})+\varepsilon_{1}(\mathrm{t})
$$$$
\text { Model 2: } \mathrm{O}_{\mathrm{KZ}}(\mathrm{t})=\mathrm{b}_{0}+\mathrm{b}_{1} \mathrm{~T}_{\mathrm{KZ}}(\mathrm{t})+\mathrm{b}_{2} \mathrm{~V}_{\mathrm{KZ}(\mathrm{t})}+\mathrm{b}_{3}
$$
$\mathrm{WS}_{\mathrm{KZ}(\mathrm{t})}+\varepsilon_{2}(\mathrm{t})$

Model 3: $\quad \mathrm{O}_{\mathrm{KZ}}(\mathrm{t})=\mathrm{b}_{0}+\mathrm{b}_{1} \mathrm{~T}_{\mathrm{KZ}}(\mathrm{t})+\mathrm{b}_{2} \mathrm{~V}_{\mathrm{KZ}(\mathrm{t})}+$ $\mathrm{b}_{3} \mathrm{WS}_{\mathrm{KZ}(\mathrm{t})}-\mathrm{b}_{4} \mathrm{RH}_{\mathrm{KZ}}(\mathrm{t})-\mathrm{b}_{5} \mathrm{TS}_{\mathrm{KZ}}(\mathrm{t})+\varepsilon_{3}(\mathrm{t})$

where $b_{0}$ is the estimated constant; $b_{1}-b_{5}$ are the regression coefficients; $\varepsilon_{1}(\mathrm{t}), \varepsilon_{2}(\mathrm{t}), \varepsilon_{3}(\mathrm{t})$ are the residuals (observed value-model predicted value) that represent the variation in $\mathrm{O}_{3}$ concentration attributed to factors other than the model selected variables (Tables 7,8 ).

Table 7 Coefficients of model

\begin{tabular}{clll}
\hline Model name & Constants & \multicolumn{2}{l}{ Regression coefficients } \\
\cline { 3 - 4 } & & $\begin{array}{l}\text { Baseline } \\
\text { component } \\
O_{\mathrm{KZ}}(t)=e(t)+\mathrm{KZ}_{15,5}\end{array}$ & $\begin{array}{l}\text { Seasonal } \\
\text { component } \\
O_{\mathrm{KZ}}(t)=S(t)= \\
\left(\mathrm{KZ}_{15,5}-\mathrm{KZ}_{365,3}\right)\end{array}$ \\
\hline Model 1 & $b_{0}$ & 1.697 & -0.004 \\
(1 predictor) & $b_{1}$ & 0.040 & 0.043 \\
Model 2 & $b_{0}$ & 1.711 & 0.004 \\
(3 predictor) & $b_{1}$ & 0.016 & 0.022 \\
& $b_{2}$ & 0.159 & 0.096 \\
Model 3 & $b_{3}$ & 0.043 & 0.054 \\
(5 predictor) & $b_{0}$ & 2.784 & 0.003 \\
& $b_{1}$ & 0.002 & 0.012 \\
& $b_{2}$ & 0.229 & 0.158 \\
& $b_{3}$ & 0.041 & 0.045 \\
& $b_{4}$ & 0.009 & 0.009 \\
& $b_{5}$ & 0.035 & 0.065 \\
\hline
\end{tabular}

Table 8 Models suggested through the step-wise regression process along with the variance explained by each model after filtering by the $\mathrm{KZ}$ filter method

\begin{tabular}{llll}
\hline Model & $\begin{array}{l}\text { Meteorological } \\
\text { variables }\end{array}$ & \multicolumn{2}{l}{ Variance explained $\left(R^{2}\right)$} \\
\cline { 3 - 4 } & & $\begin{array}{l}\text { Base line } \\
\text { component }\end{array}$ & $\begin{array}{l}\text { Seasonal } \\
\text { component }\end{array}$ \\
\hline Model 1 & $T_{\max }$ & 0.230 & 0.298 \\
Model 2 & $T_{\max } / V_{\text {avg }} / \mathrm{WS}_{\text {avg }}$ & 0.287 & 0.383 \\
Model 3 & $T_{\max } / V_{\text {avg }} / \mathrm{WS}_{\text {avg }} / \mathrm{RH}_{\text {avg }} / \mathrm{TS}$ & 0.318 & 0.430 \\
\hline
\end{tabular}




\section{References}

Ashmore MR, Bell JNB (1991) The role of ozone in global change. Ann Bot 67:39-48

Azzi M, Duc H (2008) Recent trends in ozone and particle concentrations in the Sydney (Australia) airshed. Am J Environ Sci 4:454-461. doi:10.3844/ajessp.2008

Benton J, Fuhrer J, Gimeno BS, Skarby L, Sanders G (1995) Results from the UN/ECE ICP-Crops indicate the extent of exceedance of the critical levels of ozone in Europe. Water Air Soil Poll 85:1473-1478

Brasseur GP, Kiehl JT, Müller JF, Schneider T, Granier C, Tie XX, Hauglustaine D (1998) Past and future changes in global tropospheric ozone: Impact on radiative forcing. Geophys Res Lett 25:3807-3810. doi:10.1029/1998GL900013

Carslaw DC (2005) On the changing seasonal cycles and trends of ozone in Mace Head, Ireland. Atmos Chem Phys Discuss 5:5987-6011. doi:10.5194/acpd-5-5987-2005

Castell N, Stein AF, Salvador R, Mantilla E, Millan M (2008) Analysis of tropospheric ozone concentration on a Western Mediterranean site: castellon (Spain). Environ Monit Assess 123:3-11. doi:10.5194/asr-2-113-2008

Cleveland RB, Cleveland WS, McRae JE, Terpenning I (1990) STL: a seasonal-trend decomposition procedure based on loess. J Off Stat 6:3-73

Cooper SM, Peterson DL (2000) Spatial distribution of tropospheric ozone in western Washington, USA. Environ Poll 107:339-347. doi:10.1016/S0269-7491(99)00172-4

Crutzen PJ (1974) Photochemical reactions initiated by and influencing ozone in unpolluted tropospheric air. Tellus 26:48-57

Duggal VK, Pandey GK (2002) Air quality management in Delhi, in: Better Air Quality in Asian and Pacific Rim Cities, 16-18 Dec, Hong Kong convention and exhibition Centre (HKCEC). http://www.cse.polyu.edu.hk

Gardner MW, Dorling SR (2000) Meteorologically adjusted trends in UK daily maximum surface ozone concentrations. Atmos Environ 34:171-176. doi:10.1016/S1352-2310(99)00315-5

Ghude SD, Jain SL, Arya BC, Beig G, Ahammed YN, Kumar A, Tyagi B (2008) Ozone in ambient air at a tropical megacity, Delhi: characteristics, trends and cumulative ozone exposure indices. J Atmos Chem 60:237-252. doi:10.1007/s10874-0099119-4

IMD Publication (1991) Climate of Haryana and Union Territories of Delhi and Chandigarh. State Climatological Summaries, PDGM 126/300-1991 (DSK. II):98

Jain SL, Arya BC, Kumar A, Ghude SD, Kulkarni PS (2005) Observational study of surface ozone at New Delhi, India. Int J Remot Sens 26:3515-3526. doi:10.1080/01431160500076616

Kalman RE (1960) A new approach to linear filtering and prediction problems. Trans ASME J Basic Eng 82(Series D):35-45

Khillare PS, Hoque RR, Shridhar V, Agarwal T, Balachandran S (2008) Temporal variability of benzene concentration in the ambient air of Delhi: a comparative assessment of pre- and postCNG periods. J Haz Mat 154:1013-1018. doi:10.1016/j.jhazmat. 2007.11.006

Kuebler J, Bergh H, Russell AG (2001) Long-term trends of primary and secondary pollutant concentrations in Switzerland and their response to emissions controls and economic changes. Atmos Environ 35:1351-1363. doi:10.1016/S1352-2310(00) 00401-5

Lal S, Naja M, Subbaraya BH (2000) Seasonal variations in surface ozone and its precursors over an urban site in India. Atmos Environ 34:2713-2724. doi:10.1016/S1352-2310(99)00510-5
Lin TY, Young LH, Wang CH (2001) Spatial variations of ground level ozone concentration in areas of different scales. Atmos Environ 35:5799-5807

Macauley FR (1931) The smoothing of time series. National Bureau of Economic Research, New York

Mönkkönen P, Uma R, Srinivasan D, Koponen IK, Lehtinen KEJ, Hämeri K, Suresh R, Sharma VP, Kulmala M (2004) Relationship and variations of aerosol number and $\mathrm{PM}_{10}$ mass concentration in a highly polluted urban environment-New Delhi, India. Atmos Environ 38:425-433. doi:10.1016/j.atmosenv2003.09.071

NAAQMS (2001) Air Quality in Delhi (1989-2000), NAAQMS/17/ 2000-2001. Central Pollution Control Board, Parivesh Bhawan

Nason GP, Silverman BW (1994) The discrete wavelet transforms. J Comput Graph Stat 3:163-191

Rao ST, Zurbenko IG (1994) Detecting and tracking changes in ozone air quality. J Air Waste Manag Assoc 44:1089-1092

Rao ST, Sistia G, Henry R (1992) Statistical analysis of trends in urban ozone air quality. J Air Waste Manag Assoc 42:1204-1211

Sebald L, Treffeisen R, Reimer E, Hies T (2000) Spectral analysis of air pollutants. Part 2: ozone time series. Atmos Environ 34:3503-3509. doi:10.1016/S1352-2310(00)00147-3

Sheng N, Tang UW (2012) Risk assessment of traffic-related air pollution in a world heritage city. Int J Environ Sci Tech doi. doi: 10.1007/s13762-012-0030-1

Shine KP (2001) Atmospheric ozone and climate change. Ozone-Sci Eng 23(6):429-435

Shukla A, Alam M (2010) Assessment of real world on-road vehicle emissions under dynamic urban traffic conditions in Delhi. Int J Urban Sci 14:207-220

Sillman S, Samson PJ (1995) The impact of temperature on oxidant formation in urban, polluted rural and remote environments. J Geophys Res 100:11497-11508

Singh S, Nath S, Kohli R, Singh R (2005) Aerosols over Delhi during pre-monsoon months: Characteristics and effects on surface radiation forcing. Geophys Res Lett 32:Art. No. L13808

Sreedharan CR, Tiwari VS (1971) The use of Brewer bubbler as a continuous ozone sensor. J Phys E Sc Ins 4:706-707

Srivastava A, Sengupta B, Dutta SA (2005) Source apportionment of ambient VOCs in Delhi city. Sci Total Environ 343:207-220. doi:10.1016/j.scetotenv.2004.10.008

Steinberger EH (1982) Trends in ozone concentrations in Jerusalem. Sci Total Environ 23:11-16

Tang L, Chen D, Karlsson P, Gu Y, Ou T (2009) Synoptic circulation and its influence on spring and summer surface ozone concentrations in southern Sweden. Borial Env Res 14:889-902

Tiwari VS (1973) Ozone distribution over India. Pure App Geophys V-VII:106-108

Tripathi OP, Jennings SG, O'Dowd CD, Coleman L, Leinert S, O'Leary B, Moran E, O'Doherty SJ, Spain TG (2010) Statistical analysis of eight surface ozone measurement series for various sites in Ireland. J Geophys Res 115:D19302 pp20. doi: 10.1029/ 2010JD014040

Tu J, Xia ZG, Wang H, Li W (2007) Temporal variations in surface ozone and its precursors and meteorological effects at an urban site in China. Atmos Res 85:310-337. doi:10.1016/j.atmosres. 2007.02.003

U.S. Environmental Protection Agency (2006) Data quality assessment: statistical methods for practitioners. EPA QA/G-9S. Office of Environmental Information, Washington DC 20460

Varshney CK, Aggrawal M (1992) Ozone pollution in the urban atmosphere of Delhi. Atmos Environ 26(B):291-294

Varshney CK, Aggrawal M (1993) Vertical ozone variation in the lower troposphere of Delhi. Environ Monit Assess 25:41-49 
Wise EK, Comrie AC (2005) Extending the Kolmogorov-Zurbenko Filter: application to ozone, particulate matter, and meteorological trends. J Air Waste Manag Assoc 55:108-121
Wu HWY, Chan LY (2001) Surface ozone trends in Hong-Kong in 1985-1995. Environ Int 26:213-222. doi:1016/S0160-4120(00) 00108-2 